\title{
Stimulation of molting in megalopae of the Asian shore crab Hemigrapsus sanguineus: physical and chemical cues
}

\author{
Nancy J. O'Connor* \\ Department of Biology, University of Massachusetts Dartmouth, 285 Old Westport Road, N. Dartmouth, Massachusetts 02747, USA
}

\begin{abstract}
The Asian shore crab Hemigrapsus sanguineus is a recent invader and abundant member of rocky intertidal coastlines of the eastern USA. Understanding factors influencing the settlement and metamorphosis of its larvae is important for predicting colonization of the species. For many species of brachyuran crustaceans studied to date, chemical cues in the natural environment stimulate molting of megalopae, the final larval stage, to the first crab stage, whereas physical cues alone have little or no effect. However, physical structure can influence the abundance of juvenile and adult crabs. In this study, I tested whether physical/structural and chemical cues stimulate molting of $H$. sanguineus in the laboratory. Molting rates of megalopae exposed to exudates from adult crabs ( $H$. sanguineus and the green crab Carcinus maenas) and different physical cues varying in structural complexity (rocks with or without biofilms, silt particles, nylon mesh used in aquaculture) were monitored. Megalopae molted sooner to the first crab stage in the presence of exudates of both crab species, rocks with and without biofilms, and all nylon meshes tested regardless of the size of mesh openings. By separating the effects of chemical and physical cues, this study shows both to be important during settlement and metamorphosis of Asian shore crab megalopae, potentially contributing to its successful colonization of North Atlantic coastlines.
\end{abstract}

KEY WORDS: Hemigrapsus sanguineus · Asian shore crab · Megalopa · Molting · Chemical cue · Physical cue

Resale or republication not permitted without written consent of the publisher

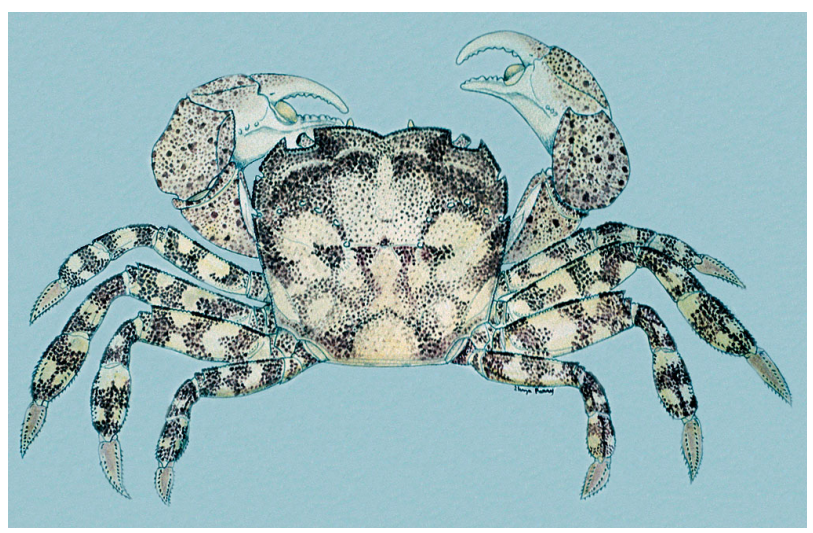

Asian shore crab Hemigrapsus sanguineus.

Watercolor painting: Elizabeth J. Perry

\section{INTRODUCTION}

Most species of crab have a complex life cycle involving a period of planktonic development through several zoeal stages, culminating in a megalopal stage that settles to the benthos and molts. Molting is accompanied by metamorphosis from the megalopal (also called postlarval) stage to the first crab stage, which resembles the adult. Molting from the planktonic megalopa to the benthic first crab stage may decrease the likelihood of predation, because fish and crab predators are more efficient at capturing megalopae than first stage crabs (Stevens \& Swiney 2005, Kim \& O'Connor 2007). Therefore, stimulation of molting upon 
contact with benthic substrata may enhance survival and fitness.

Megalopae of brachyuran decapod crustaceans exhibit flexibility in timing of molting in response to chemical cues derived from natural habitats or conspecifics (Forward et al. 2001). In most cases, the chemical cues shorten the time until molting, but cues can also retard molting (Kopin et al. 2001, O'Connor 2005). In contrast, physical cues such as clean mimics of natural substrata have little or no effect on timing of molting (reviewed by Forward et al. 2001).

However, postlarval stages of other decapods are stimulated to molt to the juvenile stage by the presence of physical structure. For example, the time to molt is shorter for lobster Homarus americanus postlarvae in containers with gravel than with sand or mud bottoms (Cobb 1968). Some species of hermit crab megalopae (Clibanarius erythropus and Pagurus granosimanus) delay molting when shells are absent (Harms 1992, Harvey \& Colasurdo 1993). Red king crab postlarvae Paralithodes camtschaticus molt sooner to the first crab stage on mesh and gravel than on sand substrata (Stevens \& Kittaka 1998).

Physical cues might be expected to influence the timing of molting of megalopae of brachyuran crab species that seek structure as juveniles and adults, such as species that inhabit rocky areas. On the east coast of North America, such species include mud crabs in the family Xanthidae and the nonindigenous crabs Carcinus maenas and Hemigrapsus sanguineus. Potential physical (or structural) cues for settlement and molting include natural substrata such as rocks and human-created substrata such as materials used in aquaculture (ropes and mesh netting).

A commonly used method to collect crab megalopae from the plankton is to suspend fibrous collectors constructed of hemp rope or hogshair filter material in seawater (Shanks 1983, van Montfrans et al. 1990, Metcalf et al. 1995, Hasek \& Rabalais 2001), or to place pieces of mesh on rocky shores (Flores et al. 2002). This suggests that fibrous and mesh materials stimulate settlement of megalopae, but the influence of those materials on molting is unknown. Both fibrous and mesh materials are commonly used in aquaculture of marine bivalves. If materials used in aquaculture stimulate settlement and molting of megalopae, future consequences could exist for aquaculture operations because crabs are frequent consumers of small bivalve molluscs used in aquaculture (MacKenzie 1977, Whetstone \& Eversole 1978, Elner 1981, Sponaugle \& Lawton 1990, Brousseau et al. 2001, Bourdeau \& O'Connor 2003).

The Asian shore crab Hemigrapsus sanguineus, native to the western North Pacific Ocean, was first noticed on the east coast of North America in the mid-1980s
(Williams \& McDermott 1990, McDermott 1998). It has since spread north to Maine and south to North Carolina and is now the most common species of intertidal crab along some shorelines (Lohrer \& Whitlatch 1997 , Ahl \& Moss 1999), where it can reach densities of

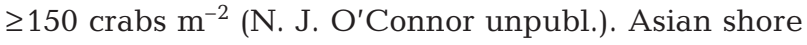
crabs have a broad, omnivorous diet and consume a variety of native species of bivalves and algae (Lohrer \& Whitlatch 1997, Brousseau et al. 2001, Ledesma \& O'Connor 2001, Bourdeau \& O'Connor 2003, Brousseau \& Baglivo 2005). H. sanguineus is most commonly found on rocky intertidal shores (Ledesma \& O'Connor 2001), but it also is present in shallow subtidal rocky areas, at the edges of salt marshes, and on floating platforms. Crab abundance is strongly associated with the presence of shelter (Fukui 1988, Lohrer et al. 2000, Ledesma \& O'Connor 2001). Megalopae are stimulated to molt in the presence of odors (exudates) from adult crabs and pebbles collected from adult habitat (Kopin et al. 2001).

The present study focused on assessing the importance of physical and chemical cues for molting of Asian shore crab Hemigrapsus sanguineus megalopae, which could have consequences for colonization of natural and artificial habitats by this non-native crab. Physical cues included rocks, sediment particles, and nylon mesh fibers and netting. Chemical cues included exudates (odors) from adult conspecifics and juvenile green crabs and biofilms.

\section{MATERIALS AND METHODS}

Rearing of larvae. Ovigerous Hemigrapsus sanguineus females were collected from local rocky intertidal habitats. Females with embryos that appeared to be close to hatching (loose and gray in color) were placed individually into $10.5 \mathrm{~cm}$ diameter dishes containing $200 \mathrm{ml}$ of $30 \mathrm{psu}$ aerated seawater filtered to $0.45 \mu \mathrm{m}$ (= FSW). The antibiotics sodium penicillin G $(21.9 \mathrm{mg}$ $\left.\mathrm{l}^{-1}\right)$ and streptomycin sulfate $\left(36.5 \mathrm{mg} \mathrm{l}^{-1}\right)$ were added to retard bacterial growth (O'Connor \& Gregg 1998). The dishes with crabs were placed in an incubator $\left(25^{\circ} \mathrm{C}, 14: 10 \mathrm{~h}\right.$ light:dark cycle). Crabs were transferred daily into clean dishes of FSW plus antibiotics until larvae hatched. The crabs were not fed during incubation.

After zoea larvae hatched, they were collected and reared in groups of $\sim 150$ in $19 \mathrm{~cm}$ diameter dishes containing $750 \mathrm{ml} \mathrm{FSW} \mathrm{and} \mathrm{antibiotics.} \mathrm{Larvae} \mathrm{were}$ reared in incubators under the conditions described above. Zoeae were transferred each day to clean dishes with fresh FSW and fed newly hatched brine shrimp Artemia sp. nauplii ad libitum. Once larvae molted to the megalopa stage (15 to $17 \mathrm{~d}$ after hatch- 
ing), they were reared in dishes as described above, but with a maximum density of $\sim 70$ megalopae per dish.

General experimental procedures. In each experiment, megalopae from a single brood were used in experiments $5 \mathrm{~d}$ after molting to the megalopal stage. Unless otherwise indicated, the same procedure was followed for all experiments. Groups of 8 to 10 megalopae (depending on the experiment) were placed in $10.5 \mathrm{~cm}$ diameter glass dishes containing $200 \mathrm{ml}$ of FSW without antibiotics. Artemia nauplii were added as food. Molting of megalopae was monitored daily at approximately the same time, when they were also fed. Newly molted crabs were not removed from the dishes in order to maintain similar densities in dishes. Cannibalism was not observed. Megalopae (and crabs) were transferred every other day to clean dishes with fresh FSW and the appropriate cue. All experiments were conducted in an incubator $\left(25^{\circ} \mathrm{C}, 14: 10 \mathrm{~h}\right.$ light:dark cycle) in the summers of 2003, 2004, and 2005.

Each dish was considered a replicate, and the cumulative proportion of molted individuals was calculated daily per dish. Statistical analysis was performed on the day an average of $\geq 50 \%$ of the megalopae had molted in at least one treatment, to provide an objective and consistent time point at which to compare treatments. A 1-way ANOVA was performed on arcsine-transformed data (if Bartlett's test for homogeneity of variances was not significant), followed by a Tukey-Kramer multiple comparisons test if the ANOVA was significant.

Experiments with chemical and chemical/physical cues. Exudates of Carcinus maenas and Hemigrapsus sanguineus: Along the rocky coastline of northeastern North America, juvenile green crabs and all stages of Asian shore crabs overlap in habitat (N. J. O'Connor unpubl.). To determine whether chemical cues from crabs in rocky habitats influence the timing of molting of Hemigrapsus sanguineus megalopae, molting responses of $H$. sanguineus megalopae in FSW was compared with molting of megalopae in water containing odors (exudates) of green crabs Carcinus maenas and conspecific adults in 2 similar experiments. In the first experiment, adult $H$. sanguineus and juvenile $C$. maenas were placed separately in beakers containing aerated FSW (2.8 to $3.5 \mathrm{~g}$ wet wt crabs $\mathrm{l}^{-1}$ FSW) for $24 \mathrm{~h}$. In the second experiment, exudate solutions were prepared using crabs at 3.3 to $3.6 \mathrm{~g}$ wet wt $\mathrm{l}^{-1}$ FSW. In both experiments, freshly made exudate solutions were placed in glass dishes and 10 megalopae were added to each dish. Control megalopae were placed in dishes containing FSW alone. After $2 \mathrm{~d}$, megalopae were transferred to clean dishes with fresh exudate solutions or FSW, as differences in molting rate, if present, were expected by then. After $4 \mathrm{~d}$, all megalopae were transferred to dishes with FSW. In the first experiment, there were 10 replicate dishes per treatment; in the second experiment there were 5 replicates per FSW treatment.

Biofilms on rocks: An experiment was conducted to compare molting of Hemigrapsus sanguineus megalopae when presented with rocks on which biofilms were allowed to develop. The specific treatments tested were (1) control FSW, (2) sterile rocks, (3) rocks on which a biofilm was allowed to develop, and (4) rocks on which a biofilm developed in the presence of adult H. sanguineus. Small (25 to $37 \mathrm{~mm}$ long) granite pebbles were scrubbed with a laboratory cleanser, rinsed thoroughly, and autoclaved to kill microorganisms on the rock surface. To create a biofilm, rocks in groups of 5 were placed in plastic containers with $1 \mathrm{l}$ of seawater (30 psu) collected from a coastal embayment and then passed through a sand filter $(\sim 20 \mu \mathrm{m})$ to remove small metazoans that could have added potential cues. In other containers with rocks, 2 adult crabs (4.6 to $5.9 \mathrm{~g}$ total wet wt) were added. All containers were aerated. Biofilms were allowed to develop for $48 \mathrm{~h}$, although microbial abundance on the rocks was not determined.

Groups of 9 megalopae were placed into dishes containing FSW alone or FSW plus a sterile rock or a rock with a biofilm; there were 10 replicate dishes for each of the 4 treatments. After $2 \mathrm{~d}$, megalopae were transferred to dishes with only FSW. Molting was monitored daily for $6 \mathrm{~d}$.

Experiments with physical/structural cues. Different physical structure/texture: Molting of Hemigrapsus sanguineus megalopae in the presence of different structures and textures was determined. Replicate dishes were prepared containing FSW alone or FSW with a sterile rock, a $5 \mathrm{~cm} \times 5 \mathrm{~cm}$ piece of netting (woven nylon with $500 \mu \mathrm{m}$ mesh), or $3.0 \mathrm{~g}$ of silt-sized (44 to $62 \mu \mathrm{m}$ ) glass microbeads. Groups of 8 megalopae were tested in 10 replicate dishes per treatment. After $2 \mathrm{~d}$ of exposure to the material (and FSW) megalopae were transferred to clean dishes with fresh treatments. After a total of $4 \mathrm{~d}$ exposure to treatments, all megalopae were transferred to clean dishes with FSW alone.

Surfactants on mesh netting: Manufacturers of mesh materials often add surfactants (surface finishing chemicals) to mesh fibers to lubricate them for the weaving process (Y. Kim, UMass Dartmouth, pers. comm.). It is possible that surfactants could act as a chemical cue for molting. To test this hypothesis, mesh was washed in an alkali solution (10 $\mathrm{g}$ baking powder in $1 \mathrm{l}$ tap water) to remove the surfactants. Squares $(5 \mathrm{~cm} \times 5 \mathrm{~cm})$ of woven nylon mesh $(500 \mu \mathrm{m})$ were cut and some were placed in the washing mixture overnight, with occasional stirring to re-suspend the baking powder. They were then rinsed several times and soaked in tap water, then rinsed several times and soaked in distilled water. Squares of washed or unwashed nylon mesh (1 square per dish) were placed in glass dishes with FSW, and megalopae 
were added in groups of 9. A control treatment of FSW alone was also tested. There were 10 replicate dishes per treatment. After $2 \mathrm{~d}$ of exposure to the mesh (and FSW) megalopae were transferred to clean dishes with fresh mesh treatments. After a total of $4 \mathrm{~d}$ exposure to treatments, all megalopae were transferred to clean dishes with FSW alone.

Mesh size: An experiment was performed to test whether megalopae had different molting responses when the size of the mesh openings was varied. Squares $(5 \mathrm{~cm} \times 5 \mathrm{~cm})$ of woven nylon mesh were cut from netting with mesh sizes $500 \mu \mathrm{m}, 1 \mathrm{~mm}, 2 \mathrm{~mm}$, and $5 \mathrm{~mm}$ and washed as described above to remove surfactants. The different mesh sizes also had different fiber widths: $0.23 \mathrm{~mm}(500 \mu \mathrm{m}), 0.33 \mathrm{~mm}(1 \mathrm{~mm})$, $0.76 \mathrm{~mm}(2 \mathrm{~mm})$, and $0.92 \mathrm{~mm}(5 \mathrm{~mm})$. Squares of washed mesh (1 square per dish) were placed in glass dishes with FSW, and megalopae were added in groups of 9. A control treatment of FSW alone was also tested. There were 10 replicates per treatment. After $2 \mathrm{~d}$ of exposure to the mesh (and FSW), megalopae were transferred to clean dishes with fresh mesh treatments. After a total of $4 \mathrm{~d}$ exposure to treatments, all megalopae were transferred to clean dishes with FSW alone.

Intact versus disassembled mesh: An experiment was performed to test whether megalopae had different molting responses when in the presence of intact mesh or mesh that had been disassembled into individual fibers. Squares $(5 \mathrm{~cm} \times 5 \mathrm{~cm})$ of woven nylon mesh were cut from netting with mesh size $500 \mu \mathrm{m}$ and washed as described above. After washing, all of the fibers were disassembled from the square mesh by gently pulling them apart with forceps and haphazardly placing them on the bottom of the dish.

In this experiment, the molting response of individual megalopae rather than groups of megalopae was determined. Megalopae were placed individually in $60 \mathrm{~mm}$ petri dishes with $10 \mathrm{ml}$ of FSW alone, or with mesh or fibers (24 megalopae per treatment). Megalopae were transferred to new dishes with fresh treatments every other day until all of the megalopae had molted. Data were analyzed using the Cox Proportional Hazards Model (Forward et al. 2001, O'Connor 2005).

\section{RESULTS}

\section{Experiments with chemical and chemical/physical cues}

\section{Exudates of Carcinus maenas and Hemigrapsus sanguineus}

In the first experiment, molting of megalopae exposed to exudates from the 2 crab species was no different from molting of megalopae exposed to FSW
(Day 10 data, 1-way ANOVA, p = 0.3506) (Fig. 1a). However, in the second experiment molting was significantly different among treatments (Day 7 data, 1 -way ANOVA, p = 0.0068) (Fig. 1b), being greatest in megalopae exposed to exudates from conspecifics, and intermediate in megalopae exposed to exudates from Carcinus maenas. Comparing the day on which $50 \%$ of megalopae in each treatment had molted, megalopae with exudates molted 2 to $3 \mathrm{~d}$ sooner than megalopae not exposed to exudates. Differences in molting responses to exudates from the 2 species became very small over time (Fig. 1b).

\section{Biofilms on rocks}

Megalopae molted in response to biofilms on rocks (Fig. 1c). On Day 8, molting varied among treatments (1-way ANOVA, p = 0.0003). Molting was significantly higher in megalopae exposed to rocks with biofilms than megalopae in control dishes, and there was no difference in response to biofilms created with or without adult conspecifics present. On average, the day on which $50 \%$ of megalopae molted occurred $\sim 2 \mathrm{~d}$ sooner in megalopae with rocks with biofilms than in control dishes. Molting in the presence of a sterile rock was not significantly different from the molting response to FSW alone or to rocks with biofilms. Many megalopae were observed under or clinging to the rocks. When dislodged from the rock, they swam back to it.

\section{Experiments with physical/structural cues}

\section{Different physical structure/texture}

The presence of structure strongly affected molting response (Day 8, 1-way ANOVA, p < 0.0001) (Fig. 1d). Molting of megalopae was greatest in the presence of mesh and next highest in response to a sterile rock. Megalopae exposed to silt-sized glass beads molted at a similar rate as those exposed to FSW alone. Megalopae and first stage crabs were observed clinging to and walking on both the rocks and the mesh.

\section{Surfactants on mesh netting}

The presence of surfactants on mesh had no effect on molting of megalopae. Molting was very high and almost identical in megalopae exposed to both washed and unwashed mesh, compared with molting in response to FSW alone (Day 7, 1-way ANOVA, p < 0.0001) (Fig. 1e). 

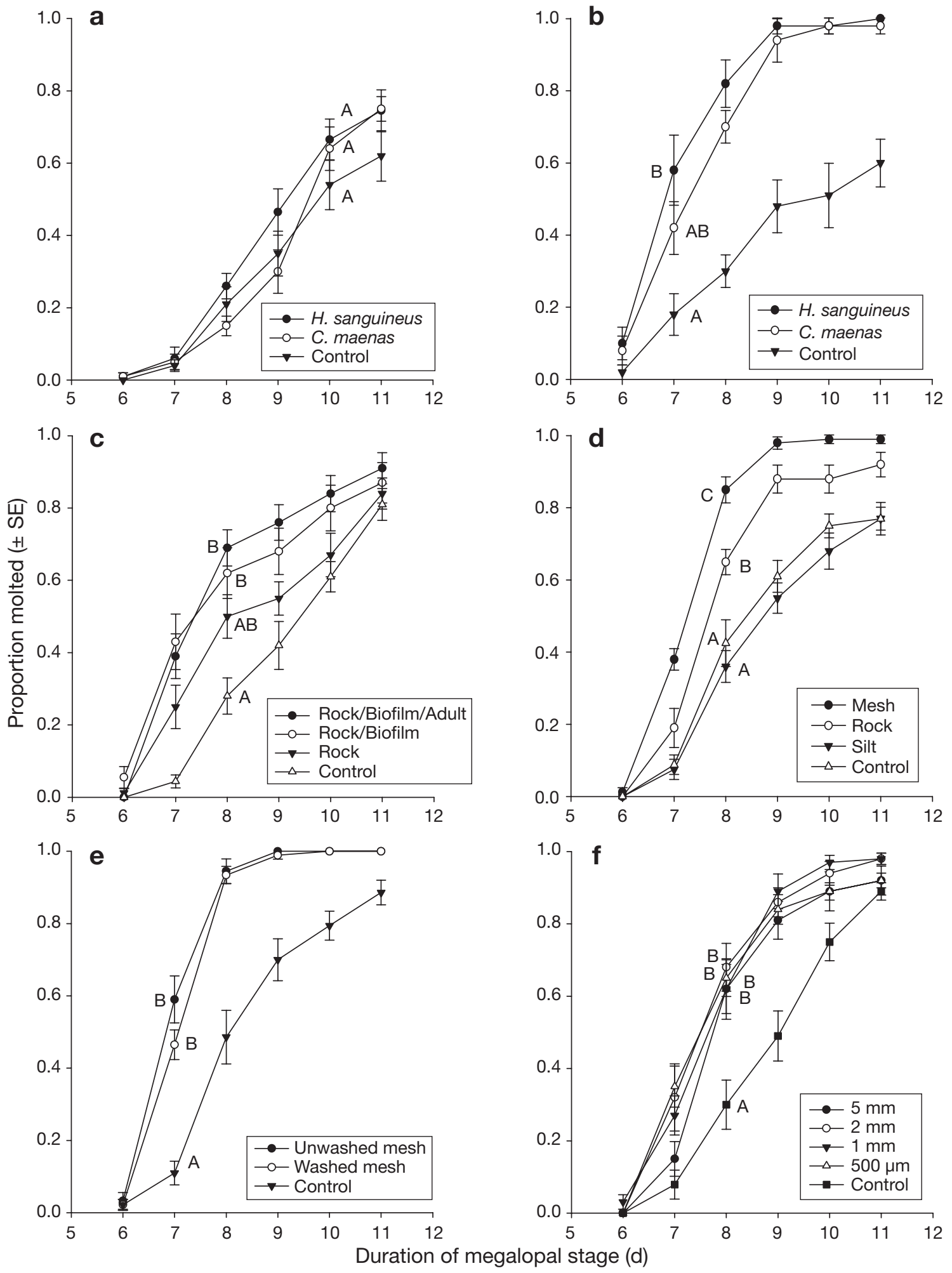

Fig. 1. Hemigrapsus sanguineus. Mean ( $\pm \mathrm{SE}$ ) proportion of megalopae (in groups of 8 to 10 ) molting to the first crab stage in response to various chemical and physical factors or to seawater alone (control). Treatments with the same uppercase letter are not significantly different. (a,b) Exudates (odors) from conspecific crabs and green crabs Carcinus maenas: (a) $\mathrm{n}=10$ and (b) $\mathrm{n}=5$ for each treatment; (c) a sterile rock, and a rock allowed to develop a biofilm with or without an adult crab present, $\mathrm{n}=10$ for each treatment; (d) nylon mesh $(500 \mu \mathrm{m})$, a sterile rock, and silt-sized glass beads, $\mathrm{n}=10$ for each treatment; (e) nylon mesh $(500 \mu \mathrm{m})$ as purchased or washed to remove surfactants, $\mathrm{n}=10$ for each treatment; (f) nylon mesh of different mesh sizes, 


\section{Mesh size}

Megalopae molted at a higher frequency in response to mesh netting, regardless of the mesh size. All mesh types produced higher, yet statistically indistinguishable, molting responses compared to molting of megalopae in FSW alone (Day 8, 1-way ANOVA, p = 0.0052) (Fig. 1f). This suggests that neither the mesh size nor the width of the mesh fibers affected molting response differentially. In addition, the day on which $\sim 50 \%$ of megalopae in all mesh treatments molted to first crab occurred $\sim 1.5 \mathrm{~d}$ earlier than for megalopae in FSW alone.

Intact versus disassembled mesh

Megalopae molted sooner in the presence of both intact and disassembled mesh, compared to molting rates of megalopae in dishes lacking mesh (Cox model, $\mathrm{p}=0.038$ and 0.017 , respectively) (Fig. 2). The mean time to molting in control dishes was $9.5 \mathrm{~d}_{i}$ in dishes with intact mesh it was $8.8 \mathrm{~d}$, and in dishes with mesh fibers it was $8.5 \mathrm{~d}$. There was no difference in time of molting in megalopae exposed to intact versus disassembled mesh (Cox model, $\mathrm{p}=0.4766$ ). By Day 13, all megalopae in all treatments had molted to crab Stage 1.

\section{DISCUSSION}

The molting response of Hemigrapsus sanguineus megalopae to crab exudates was inconsistent. In one experiment, megalopae did not respond to exudates, but in the other experiment, there was a strong molting response, even though there were fewer replicates per treatment (5 vs. 10). However, the response of mega-

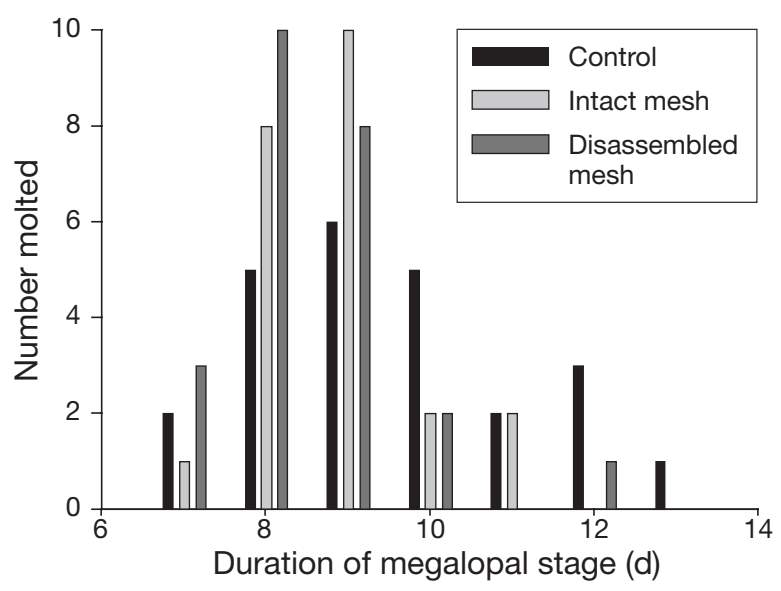

Fig. 2. Hemigrapsus sanguineus. Day of molting of individual megalopae in the presence of intact nylon mesh $(500 \mu \mathrm{m})$, fibers disassembled from nylon mesh, or to seawater alone (control) lopae to control FSW in both experiments was similar. In a pilot experiment not described here, there was also no response to crab exudates. However, Kopin et al. (2001) found stimulation of molting of $H$. sanguineus megalopae by conspecific exudate. This suggests that different broods of larvae respond differently to chemical odors (exudates) from crabs. Alternatively, the slightly higher mass:volume ratio of crabs used during preparation of exudate solutions in the second experiment could have resulted in a higher concentration of chemical cues.

Megalopae molted at approximately the same rate when exposed to exudates from either Carcinus maenas or adult Hemigrapsus sanguineus. In other species of crab, molting is more specific; megalopae typically respond to odors from conspecifics (Forward et al. 2001) or congenerics (Gebauer et al. 2002) and some crab species molt sooner only in the presence of odors from conspecifics (O'Connor \& Gregg 1998). H. sanguineus megalopae molted in response to odors from a species in a different family, C. maenas, with which it had not co-occurred before its introduction to the western North Atlantic Ocean in the mid-1980s, suggesting it has a relatively broad molting response.

Rocks with biofilms stimulated molting of Hemigrapsus sanguineus megalopae. This result was similar to the stimulatory effect of biofilms on molting of the xanthid mud crab Panopeus herbstii (Weber \& Epifanio 1996, Rodriguez \& Epifanio 2000). Biofilms created in the presence of adult crabs did not differ in effect from biofilms created without an adult. In addition, sterile rocks also slightly enhanced molting of megalopae. It is uncertain if or how the presence of adult crabs affected biofilm formation. However, biofilms are generally absorptive (Decho 1990), so exudates from the crabs might have been taken up by the biofilm on the rocks even though they did not appear to influence molting.

A structurally simple substratum lacking crevices that could provide shelter (silt-sized glass beads) had no effect on molting, whereas structurally complex substrata (sterile rocks and mesh netting) stimulated molting. In addition, megalopae appeared to be attracted to both rocks and mesh, and were often observed crawling over and under them. The nylon mesh was transparent so the darkness of the substratum was not the attractive factor. Weber \& Epifanio (1996) found that mimics of algae (plastic strips) and rocks and shells (glass pieces and marbles) had no effect on molting of Panopeus herbstii. However, plastic and glass are considerably smoother than natural rocks and mesh netting, so the surface rugosity of the substratum, or its chemical composition, might be more important than its simple physical presence.

Hemigrapsus sanguineus megalopae showed a consistent and strong positive molting response to mesh 
netting, regardless of the mesh size or whether or not the mesh was intact or disassembled into individual fibers. In prior work, intact netting did not stimulate molting of the grapsid crab Chasmagnathus granulata (Gebauer et al. 1998, 2002) although bundles of fibers did advance molting (Gebauer et al. 1998). The potential effect of mesh netting on molting of megalopae of other crab species should be tested before any generalizations about its importance can be made.

Juvenile and adult Hemigrapsus sanguineus occupy structurally complex habitats primarily in the rocky intertidal zone. Megalopae settle in similar habitats (Lohrer 2001), where both chemical (older crabs, biofilms) and physical (rocks) cues are present. Other potential physical habitat cues include organisms with mesh-like or filamentous structures such as mussel byssal threads and filamentous or branching macroalgae. Stimulation of molting of megalopae in the presence of benthic substrata that are structurally complex could lead to a reduction in predation, particularly for newly settled crabs that molt frequently and are vulnerable during and after molting.

Megalopae of other crab species (Carcinus maenas and Callinectes sapidus) settle in the field in a broad range of habitats, including mussel and oyster beds, filamentous algae, and seagrass beds (Moksnes 2002, Moksnes \& Heck 2006). The high settlement of $C$. sapidus megalopae onto artificial (plastic) seagrass (Moksnes \& Heck 2006) suggests that physical structure might provide a cue for settlement and metamorphosis, which would not be predicted by results of laboratory studies showing the high importance of chemical cues for molting (Forward et al. 1996).

A non-natural, human-created material (nylon mesh netting and fibers) strongly stimulated molting. This finding has potential implications for aquaculture, where juvenile bivalves typically are enclosed in mesh bags and cages. If mesh stimulates settlement and molting of crab megalopae in the field, a potential crab predator could take up residence with potential bivalve prey. Small crabs grow quickly, reaching $\sim 3 \mathrm{~mm}$ in carapace width (CW) after 1 mo (Epifanio et al. 1998) and growing $\sim 1 \mathrm{~mm}$ each month until mature (Fukui 1988). Hemigrapsus sanguineus of 10 to $15 \mathrm{~mm} \mathrm{CW}$ can eat mussels Mytilus edulis and oysters Crassostrea virginica $<5 \mathrm{~mm}$ in size (Brousseau et al. 2001). Therefore, the effect of $H$. sanguineus on juvenile bivalves would depend on the relative sizes of each. As H. sanguineus continues to increase in geographic range and abundance, it could become a concern for the aquaculture industry, especially if shellfish cages attract shelter-seeking juveniles as well as settling megalopae.

The present study links prior observations of settlement of megalopae in the field with cues stimulating metamorphosis of megalopae to the first crab stage in the laboratory. Fibrous materials are used successfully to passively collect crab megalopae settling from the water column (Shanks 1983, van Montfrans et al. 1990). The present study is the first to demonstrate conclusively that fibrous materials also stimulate molting in a species of brachyuran. Therefore, fibrous materials affect both behavior (settlement) and physiology (molting) of crab larvae. If physical structure stimulates molting of other species of decapod postlarvae, then care must be taken in interpreting any differences in developmental stage of postlarvae collected with physically complex passive collectors and plankton tows (Lipcius et al. 1990, Moksnes \& Wennhage 2001) because the method of collection could potentially affect the developmental stage of the postlarvae collected.

Hemigrapsus sanguineus is a non-indigenous crab in both North America (McDermott 1998) and Europe (Breton et al. 2002). Unlike most other species of crab studied to date, $H$. sanguineus megalopae do not appear to have highly specific cues for molting; a wide variety of both chemical and physical cues can stimulate molting, including human-made materials. The broad responsiveness of megalopae to potential habitat cues may have strong implications for habitat colonization and spread of this non-native species, potentially contributing to its successful establishment along both coasts of the North Atlantic Ocean.

Acknowledgements. I thank D. Beauchemin, J. Cho, G. Dobihal, and J. Rasch for assistance. R. Shadbegian provided statistical consultation. P. O. Moksnes and 2 anonymous reviewers provided helpful comments on the manuscript. The research was supported by WHOI Sea Grant project R/B-168-PD and a grant from the UMass Dartmouth Healey Endowment.

\section{LITERATURE CITED}

Ahl RS, Moss SP (1999) Status of the non-indigenous crab, Hemigrapsus sanguineus, at Greenwich Point, Connecticut. Northeast Nat 6:221-224

Bourdeau PE, O'Connor NJ (2003) Predation by the nonindigenous Asian shore crab Hemigrapsus sanguineus on macroalgae and molluscs. Northeast Nat 10:319-334

Breton G, Faasse M, Noel P, Vincent T (2002) A new alien crab in Europe: Hemigrapsus sanguineus (Decapoda: Brachyura: Grapsidae). J Crustac Biol 22:184-189

Brousseau DJ, Baglivo JA (2005) Laboratory investigations of food selection by the Asian shore crab, Hemigrapsus sanguineus: algal versus animal preference. J Crustac Biol 25: 130-134

Brousseau DJ, Filipowicz A, Baglivo JA (2001) Laboratory investigations of the effects of predator sex and size on prey selection by the Asian shore crab, Hemigrapsus sanguineus. J Exp Mar Biol Ecol 262:199-210

Cobb JS (1968) Delay of moult by the larvae of Homarus americanus. J Fish Res Board Can 25:2251-2253

Decho AW (1990) Microbial exopolymer secretions in ocean 
environments: their role(s) in food webs and marine processes. Oceanogr Mar Biol Annu Rev 28:73-153

Elner RW (1981) Diet of green crab Carcinus maenas (L.) from Port Hebert, southwestern Nova Scotia. J Shellfish Res 1: 89-94

Epifanio CE, Dittel AI, Park S, Schwalm S, Fouts A (1998) Early life history of Hemigrapsus sanguineus, a nonindigenous crab in the Middle Atlantic Bight (USA). Mar Ecol Prog Ser 170:231-238

Flores AA, Cruz J, Paula J (2002) Temporal and spatial patterns of settlement of brachyruan crab megalopae at a rocky coast in Central Portugal. Mar Ecol Prog Ser 229: 207-220

Forward RB Jr, De Vries MC, Rittschof D, Frankel DAZ, Bischoff JP, Fisher CM, Welch JM (1996) Effects of environmental cues on metamorphosis of the blue crab Callinectes sapidus. Mar Ecol Prog Ser 131:165-177

Forward RB Jr, Tankersley RA, Rittschof D (2001) Cues for metamorphosis of brachyuran crabs: a review. Am Zool 41: $1108-1122$

Fukui Y (1988) Comparative studies on the life history of the grapsid crabs (Crustacea, Brachyura) inhabiting intertidal cobble and boulder shores. Publ Seto Mar Biol Lab 33: 121-162

Gebauer P, Walter I, Anger K (1998) Effects of substratum and conspecific adults on the metamorphosis of Chasmagnathus granulata (Dana) (Decapoda: Grapsidae) megalopae. J Exp Mar Biol Ecol 223:185-198

Gebauer P, Paschke K, Anger K (2002) Metamorphosis in a semiterrestrial crab, Sesarma curacaoense: intra- and interspecific settlement cues from adult odors. J Exp Mar Biol Ecol 268:1-12

Harms J (1992) Larval development and delayed metamorphosis in the hermit crab Clibanarius erythropus (Latreille) (Crustacea, Diogenidae). J Exp Mar Biol Ecol 156:151-160

Harvey AW, Colasurdo EA (1993) Effects of shell and food availability on metamorphosis in the hermit crabs Pagurus hursutiusculus (Dana) and Pagurus granosimanus (Stimpson). J Exp Mar Biol Ecol 165:237-249

Hasek BE, Rabalais NN (2001) A comparison of molt states of blue crab megalopae, Callinectes sapidus (Rathbun), sampled with artificial collectors and plankton nets. J Exp Mar Biol Ecol 265:15-27

Kim AKA, O'Connor NJ (2007) Early stages of the Asian shore crab Hemigrapsus sanguineus as potential prey for the striped killifish Fundulus majalis. J Exp Mar Biol Ecol 346:28-35

Kopin CY, Epifanio CE, Nelson S, Stratton M (2001) Effects of chemical cues on metamorphosis of the Asian shore crab Hemigrapsus sanguineus, an invasive species on the Atlantic coast of North America. J Exp Mar Biol Ecol 265: 141-151

Ledesma ME, O'Connor NJ (2001) Habitat and diet of the non-native crab Hemigrapsus sanguineus in southeastern New England. Northeast Nat 8:63-78

Lipcius RN, Olmi EJ III, van Montfrans J (1990) Planktonic availability, molt stage and settlement of blue crab postlarvae. Mar Ecol Prog Ser 58:235-242

Lohrer AM (2001) The invasion by Hemigrapsus sanguineus in eastern North America: a review. Aquat Invaders 12: $1-11$

Lohrer AM, Whitlatch RB (1997) Ecological studies of the recently introduced Japanese shore crab (Hemigrapsus sanguineus) in eastern Long Island Sound. In: Balcom N (ed) Proc Second Northeast Conf Nonindigenous Aquatic Nuisance Species. Connecticut Sea Grant College Program CTSG-97-02, Groton, CT, p 49-60

Editorial responsibility: Otto Kinne (Editor-in-Chief), Oldendorf/Luhe, Germany
Lohrer AM, Fukui Y, Wada K, Whitlatch RB (2000) Structural complexity and vertical zonation of intertidal crabs, with focus on habitat requirements of the invasive Asian shore crab, Hemigrapsus sanguineus (de Haan). J Exp Mar Biol Ecol 244:203-217

MacKenzie CL Jr (1977) Predation on hard clam (Mercenaria mercenaria) populations. Trans Am Fish Soc 106: $530-537$

McDermott JJ (1998) The western Pacific brachyuran (Hemigrapsus sanguineus: Grapsidae), in its new habitat along the Atlantic coast of the United States: geographic distribution and ecology. ICES J Mar Sci 55:289-298

Metcalf KS, van Montfrans J, Lipcius R, Orth RJ (1995) Settlement indices for blue crab megalopae in the York River, Virginia: temporal relationships and statistical efficiency. Bull Mar Sci 57:781-792

Moksnes PO (2002) The relative importance of habitatspecific settlement, predation and juvenile dispersal for distribution and abundance of young juvenile shore crabs Carcinus maenas. J Exp Mar Biol Ecol 271:41-73

Moksnes PO, Heck KL Jr (2006) Relative importance of habitat selection and predation for the distribution of blue crab megalopae and young juveniles. Mar Ecol Prog Ser 308: 165-181

Moksnes PO, Wennhage H (2001) Methods for estimating decapod larval supply and settlement: importance of larval behavior and development stage. Mar Ecol Prog Ser 209:257-273

O'Connor NJ (2005) Influence of extracts of adult crabs on molting of fiddler crab megalopae (Uca pugnax). Mar Biol 146:753-759

O'Connor NJ, Gregg AS (1998) Influence of potential habitat cues on duration of the megalopal stage of the fiddler crab Uca pugnax. J Crustac Biol 18:700-709

Rodriguez RA, Epifanio CE (2000) Multiple cues for induction of metamorphosis in larvae of the common mud crab Panopeus herbstii. Mar Ecol Prog Ser 195:221-229

Shanks AL (1983) Surface slicks associated with tidally forced internal waves may transport pelagic larvae of benthic invertebrates and fishes shoreward. Mar Ecol Prog Ser 13: 311-315

Sponaugle S, Lawton P (1990) Portunid crab predation on juvenile hard clams: effects of substrate type and prey density. Mar Ecol Prog Ser 67:43-53

Stevens BG, Kittaka J (1998) Postlarval settling behavior, substrate preference, and time to metamorphosis for red king crab Paralithodes camtschaticus. Mar Ecol Prog Ser 167: 197-206

Stevens BG, Swiney KM (2005) Post-settlement effects of habitat type and predator size on cannibalism of glaucothoe and juveniles of red king crab Paralithodes camtschaticus. J Exp Mar Biol Ecol 321:1-11

van Montfrans J, Peery CA, Orth RJ (1990) Daily, monthly and annual settlement patterns by Callinectes sapidus and Neopanope sayi megalopae on artificial collectors deployed in The York River, Virginia: 1985-1988. Bull Mar Sci 46:214-229

Weber JC, Epifanio CE (1996) Response of mud crab (Panopeus herbstii) megalopae to cues from adult habitat. Mar Biol 126:655-661

Whetstone JM, Eversole AG (1978) Predation on hard clams, Mercenaria mercenaria, by mud crabs, Panopeus herbstii. Proc Natl Shellfish Assoc 66:42-48

Williams AB, McDermott JJ (1990) An eastern United States record for the western Indo-Pacific crab, Hemigrapsus sanguineus (Crustacea: Decapoda: Grapsidae). Proc Biol Soc Wash 103:108-109

Submitted: July 20, 2007; Accepted: November 1, 2007 Proofs received from author(s): December 5, 2007 